\title{
Structural Systems Enveloping a Sport Complex
}

\author{
Obiri Godwin Ezue, Brisibe and Warebi Gabriel* \\ Department of Architecture, Rivers State University, Nkpolu-Oroworukwo, Nigeria
}

*Corresponding author: Warebi Gabriel, Department of Architecture, Rivers State University, Nkpolu-Oroworukwo, Port Harcourt, Nigeria.

Received Date: January 26, 2020

Published Date: February 13, 2020

\section{Abstract}

Sport is a necessity for the development of sound mind and body which are needed for adequate and balanced education. Besides, it is an international phenomenon with socio-political and economic implication. This has facilitated the need for the development of sport facilities alongside other educational and social facilities in universities to enhance the participation of students in sport activities either as a full time programmed as in physical education or as a social and recreational activity. The study involves analyzing various structural systems use in enveloping sport facilities. It investigates sporting facilities where light weight structure roofing systems have been achieved at minimal cost or expenditures.

Keywords: Fabric structures; Tensioned fabric structures; Cable structures; Membrane structures; Material characteristics and fabric types

\section{Introduction}

Sports have been a central part of college life since the establishment of the first universities and schools of higher education. Students and the surrounding community congregate for athletic contests, intramural activities, and personal fitness on college campuses worldwide. In recent years Universities have seen that in order to stay competitive with other schools there is an increased need for larger, more state of the art sports and recreation facilities that will accommodate the students' needs for an attractive and efficient place to work out and participate in recreational athletic events.

Fabric structures have been in existence for thousands of years. However, only in the last fifty years have these "tents" evolved into structures utilizing the inherent structural characteristics of the membrane. While tensioned fabric structures are fascinating to engineers for realizing materials to their fullest potential, they never cease to amaze the architect in its free-flowing shape and design.

However, due to the nature of membrane structures, a conventional method of design and analysis does not suffice. Moreover, having a short history of half a century, relatively little information is available compared to conventional structures. Everything from the material selection, load considerations to the analysis method and the structural connections must be designed for the specific needs of the enveloping framework. (Miriam, 2007).

\section{Methods}

For the purpose of this paper, the case study method of research has been adopted.
Secondary sources of information shall be from studies by other researchers through books, journals, published and unpublished literature, as well as online sources : It can be used to get a new perspective on the current study, to supplement or compare the work or to use parts of it as long as the data remain relevant. The

data collected will be reviewed and used as bases for concept generation and analysis.

For this paper I have chosen to do two things: summarize empirically validated findings from other studies that are relevant to the questions of this research and add my own line of thought.

\section{Definition of Terms}

\section{Roof}

A Roof, covering of the top of a building, serving to protect against rain, snow, sunlight, wind, and extremes of temperature.

\section{Fabric structure}

In architecture, fabric structures are forms of constructed fibers that provide end users a variety of aesthetic free form building designs.

Custom-made fabric structure is engineered and fabricated to meet world-wide structural, frame retardant, weather resistance and natural force requirement.

Fabric structures are tensile structures in which a membrane is stretched to form a three-dimensional surface that can be used to create a roof, shade, or decorative component. 


\section{Tensioned fabric structures}

Tension fabric buildings are constructed using a rigid frame which can consist of timber, steel, rigid plastic, or aluminum and a sturdy outer membrane. Once the frame is erected, the fabric cover is stretched over the frame. The fabric cover is tensioned to provide the stable structural support of the building.

Fabric tensile structures is a stretched fabric material in surface tension formed to a three-dimensional surface that can be used to create a roof, shading, or decorative components by tensioning it to cables and it is constructed using a specialized fabric under tension to support self-weight and take care of the live load providing a very cost effective and covering a large distance without intermediate supports.

\section{Membrane Structures}

Membrane structures, encompassing both the tensioned fabric and the supporting structure, can span from 3 to 20 meters to spans more than 200 meters. For spans more than 200 meters, the fabric is supported by cables with steel or air so that unsupported span of the fabric is actually less than 30 meters. There are several systems adopted for tensioned fabric systems. While maintaining the concept of tension fabric design, each system is unique. These systems can be combined with each other to create interesting and even more complex designs. [1].

Membrane structures create spaces that are enclosed by tensioned membranes. At its simplest, a tent may be regarded as a membrane structure given its steel or fiberglass poles support a canvas or plastic membrane covering.

\section{Arch-supported structures}

The arch-supported membrane shape is comprised of a saddle with one curving boundary and three curving boundaries. This configuration is conceptually very pleasing since the membrane working in complete tension while the arch is ideally working in complete compression. These systems can be designed quite efficiently for spans of about 25 feet.

The interaction between the membrane and the arch, which create the saddle curvature of the fabric, allows adequate resistance against buckling for shorter span arches. In order to achieve this, the arch must be relatively stiff. Using tubular steel members with low bending stiffness is necessary [2].

\section{Structures with primary supports}

Saddle surfaces can also be created in the membrane by primary point supports that, unlike the arch-supported system, do not lie on the same plane. Care must be taken that the cable stays are in tension regardless the loading.

An example of primary point support structures is the simple cone structure that consists of a mast in the center of the membrane. This can be repeated in groups to enclose a larger area of space. Although this can fulfil many applications and provide the greatest range of shapes, the existence of a big structural element in the center of the utilized area can become awkward and obstructive [3].

\section{Ridge-and-valley structures}

The concept of ridge-and valley structures is based on the creating of slight saddle by laying cables in an adjacent pattern with opposing curvature. The membrane is created and restrained by the alternating ridge and valley cables.

The curvature created is quite small and therefore this type of structure cannot be realized in all situations. Many tests and loading scenarios must be reviewed before deciding the feasibility of this kind of design [3].

\section{Mast structures}

In tensioned fabric structures where the supporting structure consists of masts, fabric is suspended from cables hung off masts or other compression elements. This kind of system is ideal for long span roofs. There are many forms of mast structures. The main three forms are the following: masts with hinged supports stabilized with cable stays, masts with hinged supports stabilized by the membrane and masts with fixed supports.

The masts must support both axial loading and lateral wind and dead loads (for angled masts). To resist buckling, which the masts are highly susceptible as a result of the axial forces increasing structure the moment stresses, the masts are constructed in lattices. The hinged base must be able to initially roll when the masts rotate, but after 2 degrees of rotation, the hinge must be able to slide. Care must be taken through construction and materials to ensure that excess friction does not impede this action [1].

\section{Case Study: The bird nest Beijing Olympic Stadium:}

Owner; Chinese Government

Designed by Herzog and Meuron, Structural engineer; Arup

Location; 1 National Stadium South Road, Beijing, Chine.

Capacity; 91,000 (2008 Olympic), 254,600sqm

Height; 70meters, Width; 296meters, Length; 320meters

Structural Engineer; Ove Arup \& Partners.

Construction; 12.2002-06.2008

Cost; $\$ 300 \mathrm{~m}$

Inauguration; 28.06.2008 (Figure 1)

The floor layout of the bird next Beijing Olympic Stadium. The structure defines an intermediate space between the plaza and the field, the randomness of everyday life and the ritual of performance. Restaurants, bars, shops and lavatories are integrated within the maze of the columns at different levels, giving spectators the experience of moving though a benign version of a Piranesi prison, even as they satisfy prosaic needs (Figure 2).

The loads at each intersection are split between the members and transferred downward. The red points indicate the transfer connections were load impact is felt most significantly. The roof of the bird nest stadium is covered with a double-layer membrane structure (on rigid steel support), with a transparent ETFE (ethylene tetra-fluoro-ethylene) membrane fixed on the upper part of the roofing structure and a translucent PTFE (poly-tetra-fluoroethylene) membrane fixed on its lower part. 


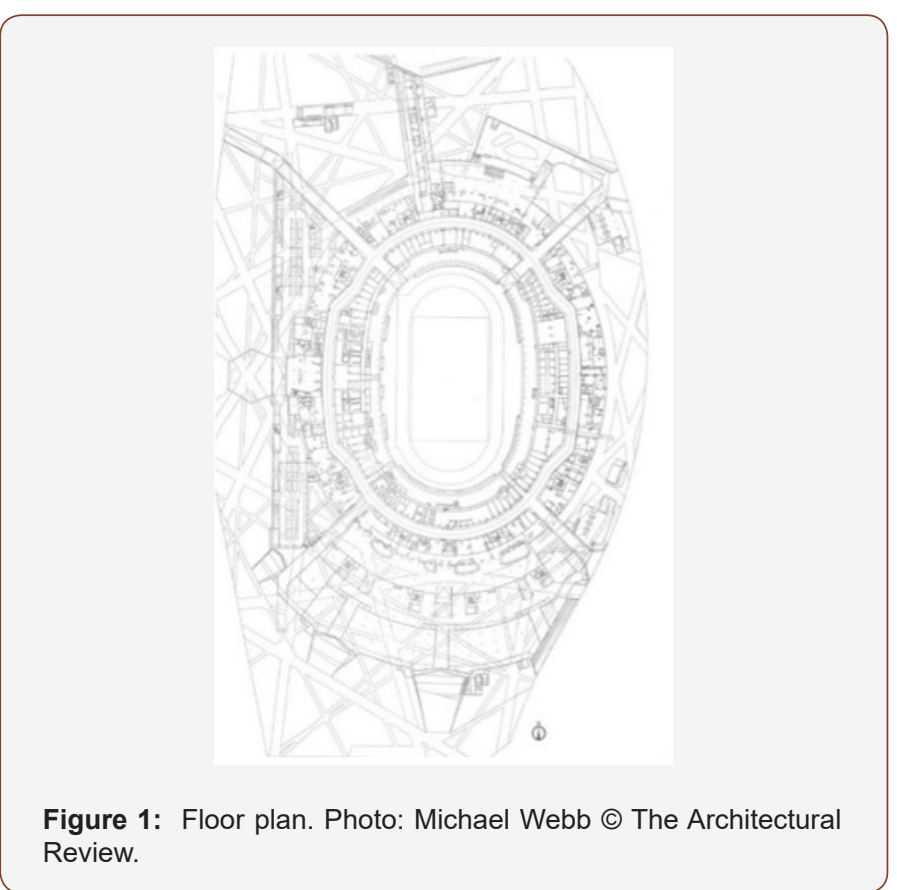

Figure
Review.

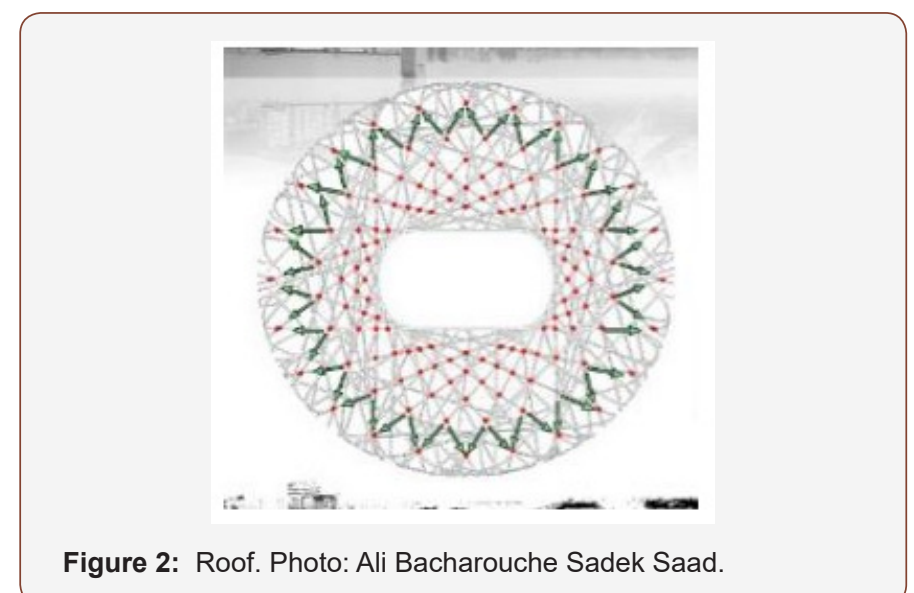

A PTFE acoustic ceiling is also attached to the side walls of the inner ring.

The spaces in the structure of the stadium are filled with inflated ETFE cushions. On the façade, the inflated cushions are mounted on the inside of the structure where necessary, to provide wind protection.

\section{Material Characteristics}

The selection of membrane material is important to the successful design of the tensioned fabric structure. The material contributes to the structural function of the system, as well as other important properties involving durability, insulation, light transmission and fire protection. Also, the membrane component of the structure determines the long-term appearance of the structure for it is the most visible element of the structure.

Currently, glass and polyester laminates, composites and fluoroplastic films are most popular. When selecting a membrane, the most important qualities to consider are the mechanical tensile strength and the elastic properties. Due to this, $90 \%$ of all weatherproof tensile fabric structure projects have used the following three specific membrane materials: Polytetrafluoroethylene (PTFE), polyvinylchloride (PVC) and ethylenetetrafluorethylene (ETFE) [2]. These materials are preferable in tensile fabric structures for an array of reasons. Not only do they have the structural ability to support such structures, these materials have been in use for the past 50 years and therefore behaviour data of these materials are abundant. These materials have become standardized and therefore the ease of acquiring and designing for these materials are higher than others.

\section{Membrane Criteria}

There are several parameters to consider when selecting the type of membrane fabric to employ. Of these, the most important are the mechanical properties, durability, light transmission, fire resistance and economic feasibility. For common materials used in practice, such as PTFE and PVC, material behaviors and characteristics have been well recorded. However, for newer materials and innovative applications, there are a wide range of tests that can be performed to get an idea of the properties and qualities of the material.

\section{Mechanical properties}

The mechanical properties of most importance to the designer are the tensile strength, which measures the force required to rupture the material, tear strength, which is the resistance to propagate an existing tear, and elastic properties, such as stiffness, which is the relationship between the modulus of elasticity and the area of the cross section of fibers [4].

\section{Durability}

The life span of the membrane structure strongly depends on the durability of the membrane fabric. Its durability is greatly influenced by the resistance to degrading from UV radiation and wicking, attacks from organic matter, and the maintaining of seam strength. Vandalism and soiling can also affect the durability of the membrane [4].

\section{Light transmission}

When designing a tensioned fabric structure, great consideration is given to the light transmission, absorption and reflection of the structure. This will ultimately affect the appearance and some aspects of the energy behaviour of the structure [4].

\section{Fire resistance}

Fire resistance is also an extremely important factor for safety. All materials are required to undergo the following standard fire tests: NFPA 701 Fire Tests for Flame-Resistant Textiles and Films (NFPA 1999).

\section{Fabric Types}

The oldest and most commonly used fabrics are coatings or laminates over polyester fabric. Different kinds of coatings are employed for different desired characteristics [4].

\section{Polyvinylchloride (PVC) - coated polyester fabric}

Polyvinylchloride (PVC) coated polyester fabrics have been used and tested since the 1960's. The wide use of this material is due to their low cost, as well as their ease of handle. However, their life expectancy is only 10-15 years and fire ratings can be improved. The PVC coated polyester has tensile strength from $350 \mathrm{MPa}$ to 
1,200 MPa and a strip tensile strength of $3,100 \mathrm{~N} / 5 \mathrm{~cm}$ to 5,800 $\mathrm{N} / 5 \mathrm{~cm}$ for membranes weighing $800 \mathrm{~g} / \mathrm{m}^{2}$ to $1,100 \mathrm{~g} / \mathrm{m}^{2}$ [2].

The prestress levels of PVC coated polyester fabric range from 1-4 kN per meter [5]. The PVC coating helps the material to achieve high tear strength for the soft PVC chains around the fibres at the tear to resist further tearing. PVC also has moderate stiffness as well as moderate behaviour to creep. Although this at times requires pretensioning of the fabric, the moderate behaviour to creep allows for some flexibility in matching fabricated components and small errors in fabrication will not result in overstress or wrinkles in the fabric.

PVC-coating protects the fabric from UV radiation degradation for roughly 10 to 15 years [2]. Although additional topcoats to protect from UV radiation can prolong the life span of the fabric, it is not very effective. PVC coated polyester can achieve light translucency of up to 22 percent and although this fabric is not deemed incombustible, it is classified as a flame retardant. Due to the fact that high temperatures create holes in the material that allow the smoke and heat to dissipate through the membrane, its incombustible nature can add to the overall safety of the structure in a fire hazard.

\section{Polytetrafluoroethylene (PTFE)- coated fiberglass}

Another type of membrane fabric commonly used in practice is Polytetrafluoroethylene (PTFE)-coated fiberglass. This material was developed in 1969 when fiberglass fabric was coated with Teflon resin. This new material advancement was a landmark in time for tension fabric structures for it was incombustible, resisted soiling and promised a more durable and therefore longer life span to membrane structures. However, this material was very expensive and had a low resistance to cracking compared to PVC coated polyester fabric. Therefore, PTFE-coated fiberglass became the material to use in long-lasting iconic architectural applications, while PVC-coated polyester fabric continued to be used for temporary, portable structures that can withstand the effects of being repeatedly erected.

The mechanical properties of PTFE coated fiberglass are 3,500 MPa and the strip tensile strength range from $1,600 \mathrm{~N} / 5 \mathrm{~cm}$ to 8,800 $\mathrm{N} / 5 \mathrm{~cm}$. These strengths allow membranes to stretch long spans with minimal curvature. However, the tear strength of PTFE-coated fiberglass is relatively low, having only $80 \mathrm{~N}$ to $550 \mathrm{~N}$ of strength to resist tears from propagating. The prestress levels range from 6-8 kN/m, 4-6 kN/m and 1-2 kN/m for heavy, light and light lining PTFE coated fiberglass fabrics, respectively [5].

Case studies have proved that PTFE-coated fiberglass fabric has an expected life span of over 30 years. Structures inspected at 30 years of age have no need of replacement due to wear and degradation. The several coats of PTFE make the fabric nearly unsusceptible to any damage due to UV radiation as well as chemical attack and wide temperature variation. In one case study of the La Verne structure erected in 1973, pre-stress levels of the fabric remained relatively uniform and near the original levels after 6 years [2]. This shows that the fabric does not creep and distort over time. In fact, the creep was measured to be only a third of its PVCcoated polyester fabric counterpart. However, there are negative aspects of this material. Since PTFE-coated fiberglass fabric has low tear strength, its vulnerability to tears and rips due to vandalism and structural overloading increases substantially. Also, fiberglass is vulnerable to wicking from edges exposed to water. However, this can be mitigated by water-repellent coating. The cost of PTFEcoated fiberglass fabric is quite expensive.

\section{Ethylene-tetra-fluorethylene (ETFE) film}

Films are also used to make up a membrane fabric. In actuality, although the films do not depend on any property of the woven fabric in the middle, without it, it cannot be considered a fabric. One commonly used film is ethylene-tetra-fluoroethylene polymer (ETFE). The tensile strength of $0.1 \mathrm{~mm}$ thick film is $225 \mathrm{~N} / 5 \mathrm{~cm}$-only $5 \%$ of PVC and PTFE-coated fabrics. These films continue to creep under load, unlike the PTFE-coated fiberglass fabric. The film yields after elongating $3 \%$ and ruptures at $200 \%$ of its original length [2]. This behaviour gives ETFE film very high tear strength. It is possible to use composite woven fabric in between the film to increase the overall tensile strength.

Although there are limited tests, films, which exclude the performance of the woven centres, can be expected to endure 15 years facing the environmental elements.

However, the durability, as well as the light transmission, fire resistance and cost, all depend greatly on the scale and design of the material and structure (Figure 3\&4).

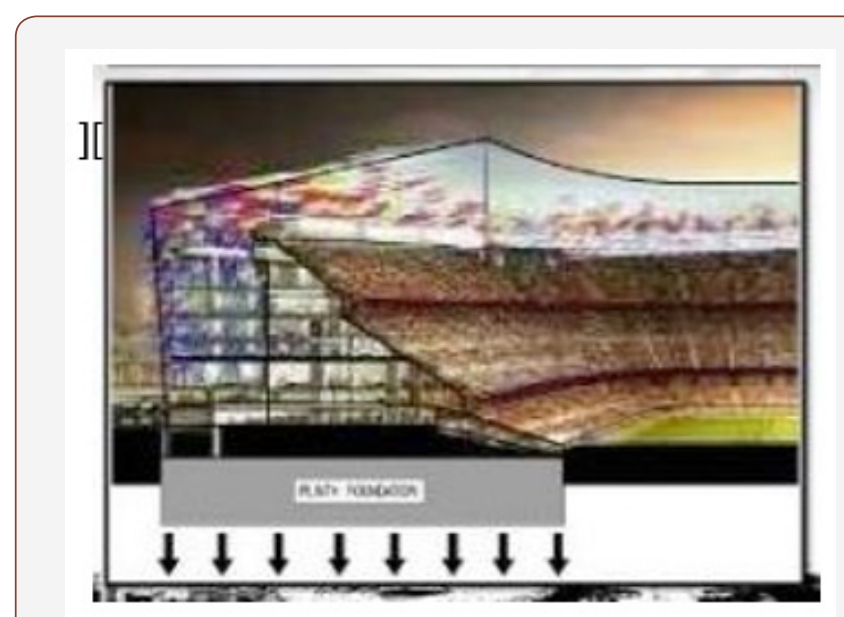

Figure 3: Section. Photo: Ali Bacharouche Sadek Saad.

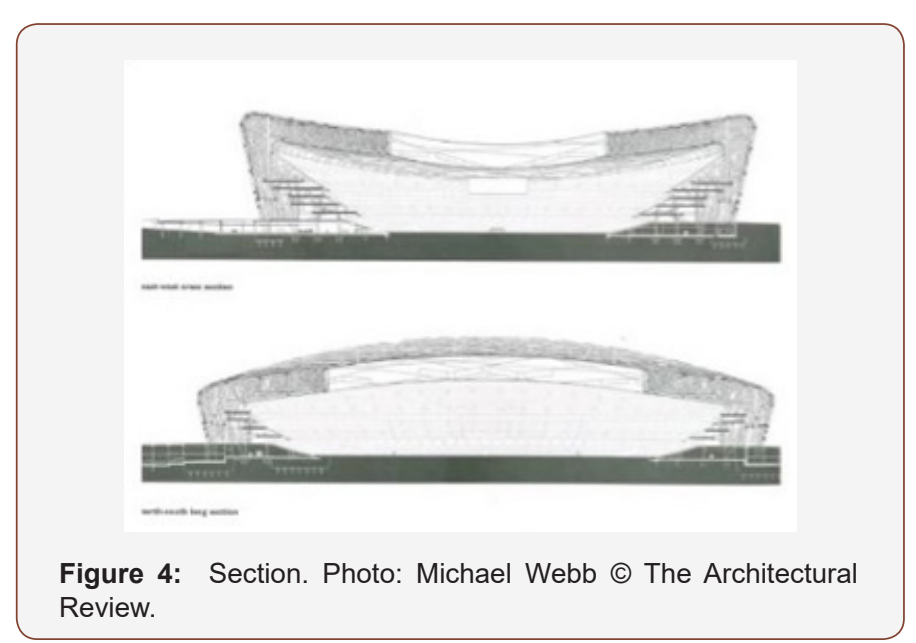


The core portion of the building carries the dead load of the concrete structure as well as the live load of people totaling to 13,122 tons. The load id transferred directly to the plinth foundation as distributed load.

\section{Horizontal Load}

The structure must resist a total of 56,625 tons of vertical load. The Steel structure itself must resist its own load of 42,000 tons and 11,625 tons of live load, totaling in 53,625 tons. The Plinth type of the foundation is essential to carry such a load, which is evenly distributed.

Each member of the steel "Nest" is designed carefully to carry its own weight of 42, 000 tons loads. The overall shape appears to be random, but it follows strict geometric rules.

The loads at each intersection are split between the members and transferred downward as indicated below (Figure 5).

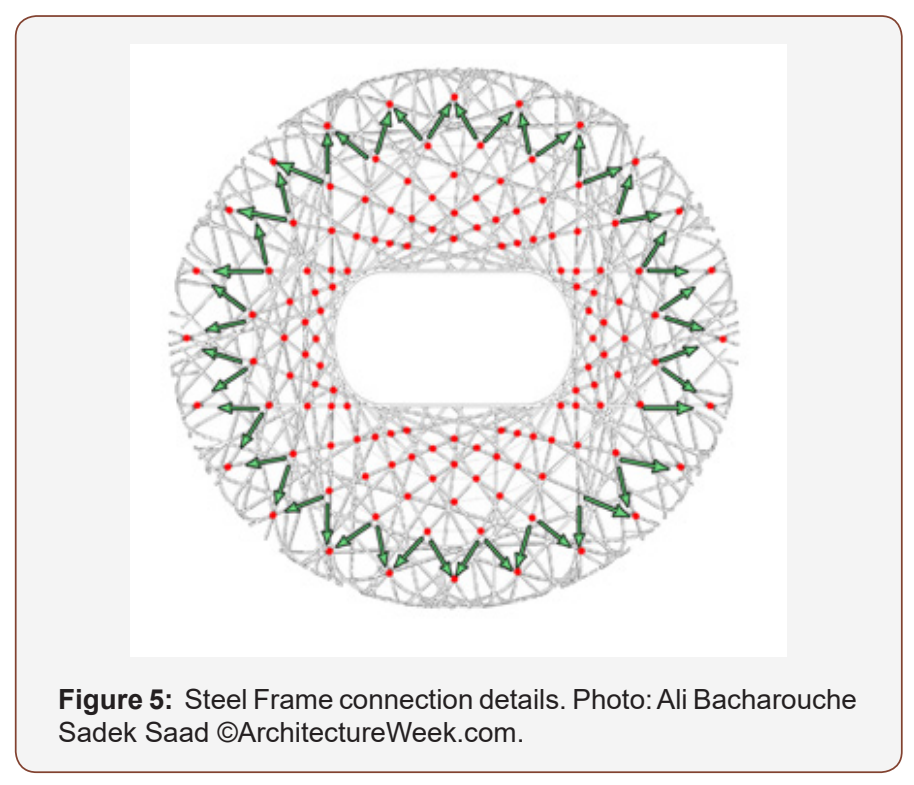

Figure 5: Steel Frame connection details. Photo: Ali Bacharouche Sadek Saad @ArchitectureWeek.com.

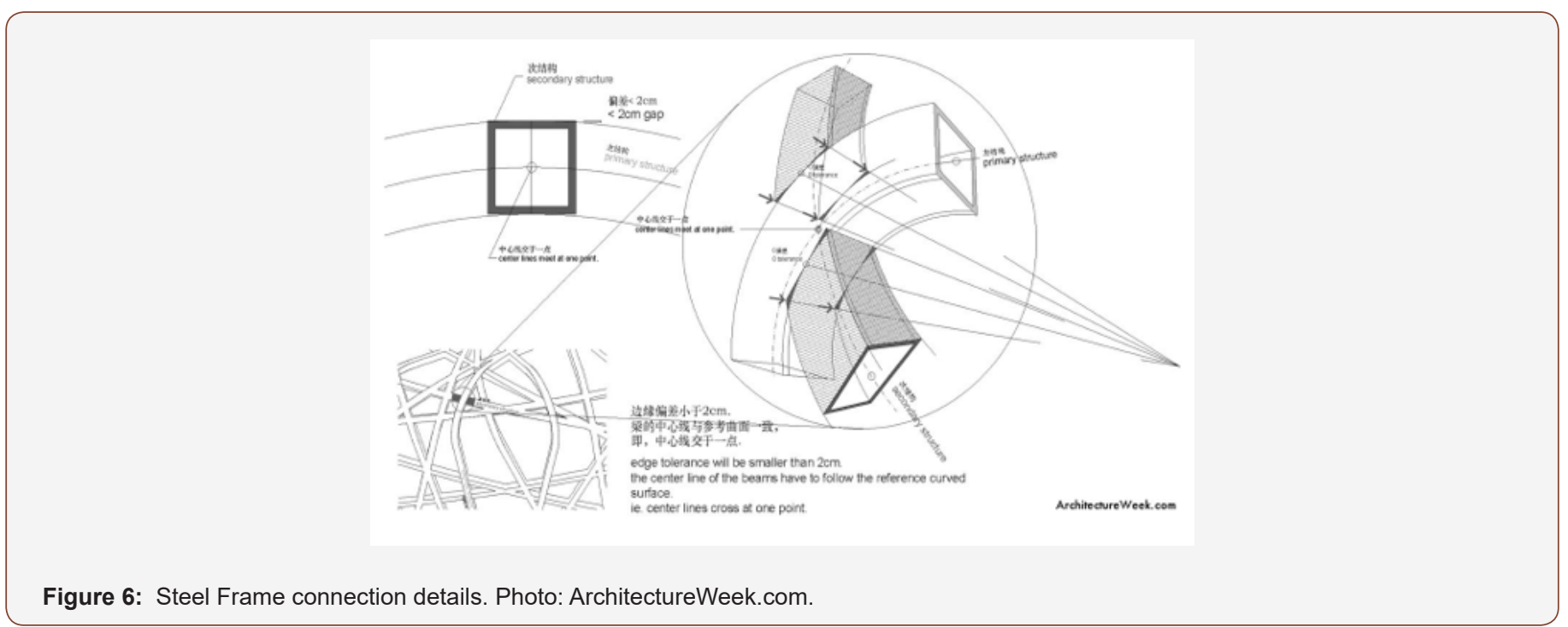

The red points indicate the transfer connections were load impact is felt most significantly. The below image identifies the primary and secondary members. the secondary members had to be welded on two sides of primary members. The steel envelope is constructed of 22.5 miles of steel and it took about 700 welders to complete the task (Figure 6).

The core portion of the building carries the dead load of the concrete structure as well as the live load of people totaling to 13,122 tons. The load is transferred directly to the plinth foundation as distributed load.

\section{Lateral Loads}

The massive steel structure resists lateral loads in a similar manner as the horizontal ones. In addition, instead of the loads hitting the structure and following it downwards and upwards it is broken down through the lattice of steel while being weakened and providing natural ventilation in the building [6-9].

The structural elements mutually support each other and converge into a spatial grid-like formation, in which facades, stairs, bowl structures and roof are integrated (Figure 7).

\section{Earthquake Loads}

The Beijing National Stadium was designed with earthquake loads in mind, because Beijing is prone to seismic events. The outer steel structure is completely separate from the inner stadium seating area and is placed 50 feet apart. this placement allows the two structures move independently in case of an earthquake. Steel has a rather high modulus of elasticity as compared to the concrete, therefore the entire outer structure could be put together as a unit and withstand earthquakes. The core of the stadium was constructed out of the pre-cast reinforced concrete. Because concrete has significantly lower modulus of elasticity, it was decided into eight individual sections. this division allows each portion of structure to move independently of the other in case of seismic motion causing minimal amount of damage (Figure 8).

First set of 24 beams in the form of trusses encircling the concrete bowl. The stadium is earthquake proof 1000 tons each.

The second set of beams fills in the empty spaces of the beams of the first set, they link all the beams to form a braided structure. The Beijing Bird Nest is designed to withstand earthquake rated at 8.0 on the Richter scale. 


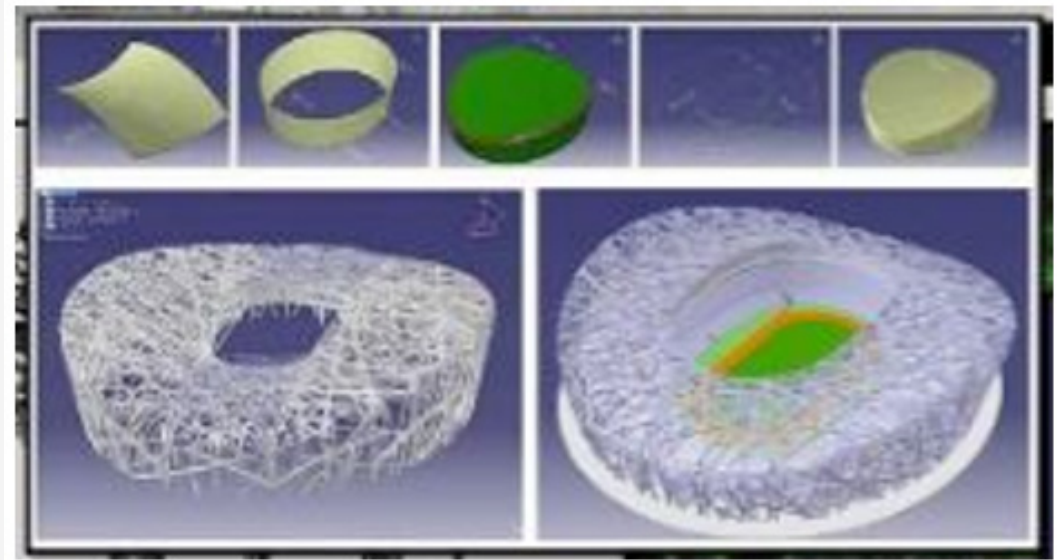

Figure 7: Steel Structures. Photo: Ali Bacharouche Sadek Saad.

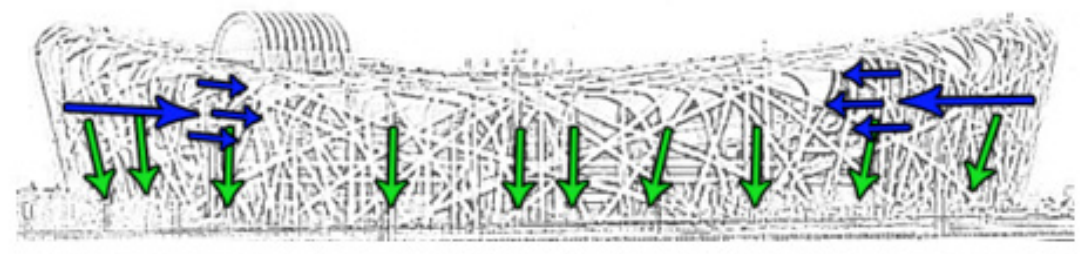

Figure 8: Steel Frame with Earthquake load in mind. Photo: ArchitectureWeek.com.].

A third set of beams support the stairways that connect the multiple levels and provides a frame for the roof membrane covering $[10,11]$ (Figure 9).
The stadium uses geothermal energy to chill and heat water that runs through the HVAC system. The piping to do that is located beneath the main athletic field.

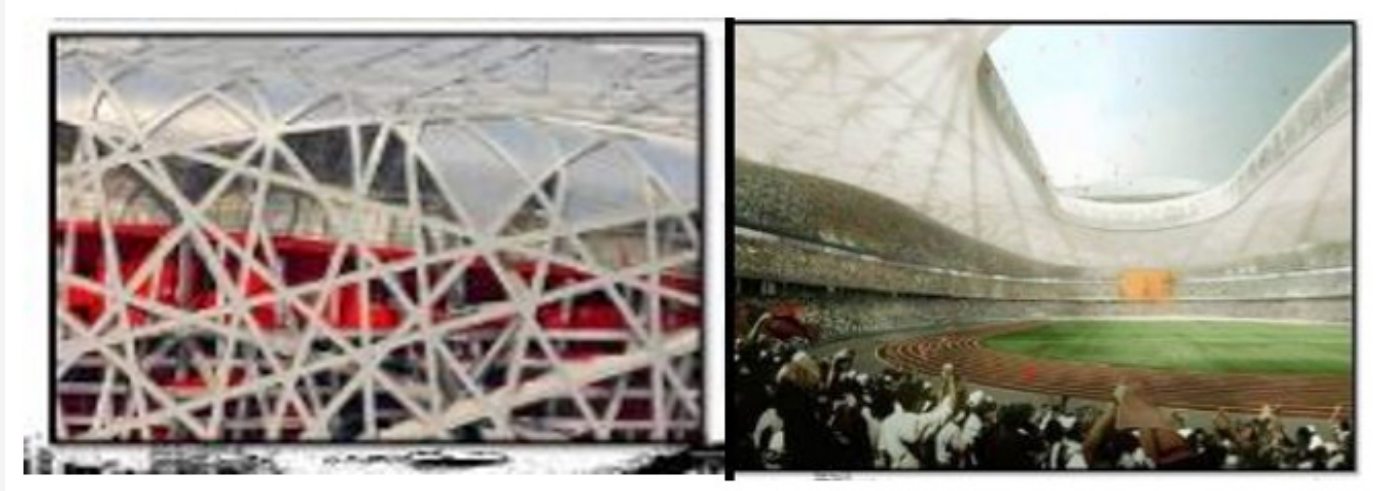

Figure 9: Sustainability in the building. Photo: Ali Bacharouche Sadek Saad.

Maximum amount of natural lighting as possible. The membrane provides rain and wind protection. It also saves energy. Sunlight filters through the roof to light the building and keep noise in.

\section{Conclusion}

Though the sport complex is not a new building type, but the information was sort, so as to gain knowledge. It is hoped that the sport facility will enhance the development of sport in its environs and also make it possible for people to participate actively in sporting activities.

This research work has identified critical dimensions from which sports participation can be improved, with the ultimate aim is to provide a permanent solution to the infrastructure related concerns of sports and thus to highlight the effects of modern materials and methods in enveloping modern-day design and construction of sport infrastructure, and improving participants well-being in this facilities. As such, it improves the already existing bulk of knowledge on modern day roofing materials and sports infrastructural concerns. it has also primed new dimensions of thought for knowledge discovery and the further promotion of research as it suggests the opportunity for the provision of facilities for human kinetics and physical education studies and practice. 


\section{Acknowledgement}

None.

\section{Conflict of Interest}

No conflict of interest.

\section{References}

1. Koch, Klaus Michael, Habermann, Karl J (2004) Membrane Structures: Innovative Building with Film and Fabric, Prestel, Munich, USA.

2. Huntington, Craig G (2004) The Tensioned Fabric Roof. American Society of Civil Engineers, Reston, UK.

3. Miriam ES (2007) The Design and Analysis of Tension Fabric Structures.

4. Shaeffer RE (1996) Tensioned Fabric Structures: A Practical Introduction, American Society of Civil Engineers Press. New York, USA.
5. Barnes, Michael, Dickson, Michael (2000) Widespan Roof Structures. T Telford, ASCE Press, UK.

6. (2019) Long span and complex Structures.

7. (2019) Long span buildings.

8. M Majowiecki (1992) Conceptual design of some long span sport structures". Innovative large span structures, IASS Congress, Toronto, Canada.

9. M Majowiecki (1990) Observations on theoretical and experimental investigations on lightweight wide span coverings. International Association for Wind Engineering, ANIV.

10. Roland, Conrad, Frei Otto (1970) Tension Structures. Translated by Amerongen CV, New York, USA.

11. S Dong, Y Zhao, D Xing (2012) Application and development of modern long-span structures in china. Front Struc Civ Eng 6(3): 224-239. 